\title{
An effective network reconfiguration approach of radial distribution system for loss minimization and voltage profile improvement
}

\author{
Surender Reddy Salkuti ${ }^{1}$, Neelakanteshwar Rao Battu ${ }^{2}$ \\ ${ }^{1}$ Department of Railroad and Electrical Engineering, Woosong University, Daejeon, Republic of Korea \\ ${ }^{2}$ Department of Electrical and Electronics Engineering, VNR Vignana Jyothi Institute of Engineering and Technology,
} Telangana, India

\begin{tabular}{l} 
Article Info \\
\hline Article history: \\
Received Feb 11, 2021 \\
Revised Apr 30, 2021 \\
Accepted Jun 23, 2021
\end{tabular}

\section{Keywords:}

Distribution load flow

Distribution network

Power losses

Reconfiguration

Voltage profile

\section{Corresponding Author:}

Surender Reddy Salkuti

Department of Railroad and Electrical Engineering

Woosong University

17-2, Jayang-Dong, Dong-Gu, Daejeon 34606, Republic of Korea

Email: surender@wsu.ac.kr

\begin{abstract}
Distribution system represents a crucial portion of power system as it is the connection between the bulk power transmission network and the customers connected at load point. Distribution networks are increasing in size and are spread too far. Low reactance to resistance ratio and large size of network leads to higher power losses in lines and low node voltage at customer end. High power losses reduce the efficiency and affect the economy. Therefore, in this paper an algorithm for reconfiguration of distribution system for loss reduction and voltage profile enhancement is proposed. The proposed reconfiguration approach has been applied to 16 bus radial distribution system (RDS).
\end{abstract}

This is an open access article under the CC BY-SA license.

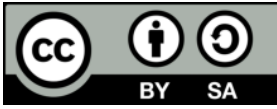

\section{INTRODUCTION}

The electricity generated by power stations is transmitted to distribution networks through transmission lines. Distribution networks in-turn feed electricity to their customers. Electric power is typically provided to consumers at low voltage. Distribution network with low voltage for consumers is achieved, since it is connection to the high voltage line with the low voltage customers. This tends to increasing of power losses by comparing with the system of transmission, approximately $12.8 \%$ generation wasted by losses in the total generation of power [1]. Real and the reactive components of branch currents usually cause the power loss. With the reconfiguration of the network the losses caused by reactive branch current components can be that. The reconfigured network reduces the power losses, increases the voltage profile of the network. The important factor that influences network reconfiguration is altering the topology of the system for efficient operation. But each distribution feeder consists of different combination of loads [2].

Settings of the distribution network can reduce missing settings by means of the tie and sectional switches as well as boost the voltage profile. Not only would the operating environments improve, but the system's hardware features would be used entirely. Configuring the feeder will require load transfers places that are relatively slightly loaded from heavily loaded areas [3]. Configuring the delivery network to 
minimize loss can be complicated combinatorial optimization problem since several switching combinations are involved in reconfiguration. The two groups are listed in most current reconfiguration algorithms. Upon the first branch exchange, during the workable radial set-up, the system runs, thus opening and closing the algorithm of candidate in pairs [4].

S. Essallah and A. Khedher [5] proposes a mixed particle swarm optimization (PSO) methodology for the minimization of active power loss and the voltage profile improvement in the distribution network. An improved selective binary PSO algorithm for solving the distribution networks reconfiguration is proposed in [6]. A. A. M. Raposo, A. B. Rodrigues, M. G. da Silva [7] proposes a new method that considers the meter placement along with the reconfiguration of RDSs for the reduction of annual energy loss. A new supply restoration and reconfiguration approach based on the enhanced binary genetic algorithm is proposed in [8]. J. Shukla, B. K. Panigrahi, and P. K. Ray [9] proposes an optimal reconfiguration model with probabilistic stability constraints with correlation and small signal stability for distribution network. A methodology for the reconfiguration associated with capacitor allocation to minimize energy losses on RDSs considering different load levels is proposed in [10]. An approach for the RDSs reconfiguration based on bio-inspired evolutionary artificial immune system algorithm to minimize energy losses is proposed in [11].

Distribution networks have increased and spread too far, resulting in higher network losses and having less voltage control. Hence requirement of an effective and secure method of network reconfiguration is now most important and relevant [12]. In this paper, network reconfiguration is performed on radial distribution system (RDS) for loss reduction and improvement of voltage profile. There are two matrices that are built in this work; they are branch current to bus voltage (BCBV) matrix, bus injection to bus current (BIBC) matrix, and the product of above matrices provides us solutions for load flow analysis. The conventional methods of load flow that are used in transmission systems are not applicable to distribution systems. In this work, the forward-backward sweep approach of load flow analysis is used [13]. In this work, the reconfiguration of the network is done for 16 RDS and the obtained results are very promising.

\section{LOAD FLOW ANALYSIS OF RADIAL DISTRIBUTION SYSTEM}

Standard algorithms such as Newton-Raphson method of load flows can be used with transmission systems. But due to weak reactance to resistance ratio of the distribution system, convergence rate of such algorithms is very slow [14], [15]. Distribution system load flows are developed to get used in weak reactance to resistance ratio systems. Certain software programs are explicitly designed for the distribution systems. Such programs would be much effective, easier, have less memory requirements and reasonable reliability [16]. The BIBC matrix [17] can be obtained by using the branch and node currents of a distribution network and it can be expressed as,

$$
\left[I_{\text {branch }}\right]=[B I B C]\left[I_{\text {node }}\right]
$$

The BCBV matrix can be expressed as,

$$
[\Delta V]=[B C B V]\left[I_{\text {branch }}\right]
$$

Since the branch current is given in (1), so one can substitute it in (2), then the obtained equation is [18],

$$
[\Delta V]=[B C B V][B I B C]\left[I_{\text {node }}\right]
$$

The distribution load flow (DLF) matrix is obtained by multiplying both [BIBC] and [BIBC] matrices,

$$
[\Delta V]=[D L F]\left[I_{\text {node }}\right]
$$

BIBC and BCBV product matrices are based upon their system topologies. The DLF matrix stays constant throughout the iterations if the device configuration does not change [19], [20]. The only modifications that occur throughout the load flow process are to node current vector and to voltage correction $\operatorname{vector}(\Delta \mathrm{V})[21]$.

\subsection{Distribution load flow algorithm}

The DLF for radial distribution network can be analysed using the following steps:

Step 1: Enter input data of the system.

Step 2: Formulate and obtain BIBC matrix.

Step 3: Formulate and obtain BCBV matrix. 
Step 4: Form the DLF matrix by using,

$$
[\Delta V]=[B C B V][B I B C]\left[I_{\text {node }}^{k}\right]
$$

Step 5: Set the iteration count, $\mathrm{k}=1$.

Step 6: Rewrite the voltages as shown in,

$$
\begin{aligned}
& I_{i}^{k}=\left(\frac{P_{i}+j Q_{i}}{V_{j}^{k}}\right)^{*} \\
& {\left[\Delta V^{k}\right]=[D L F]\left[I^{k}\right]} \\
& {\left[V^{k}\right]=\left[V_{1}\right]-\left[\Delta V^{k}\right]}
\end{aligned}
$$

Step 7: If $I_{i}^{k}-I_{i}^{k}>$ tolerance go to next step, else print the results.

Step 8: $\mathrm{k}=\mathrm{k}+1$

Step 9: Go to Step 6.

\section{NETWORK RECONFIGURATION}

Reconfiguration of RDS refers to opening and closing operation of sectionalizing and tie switches respectively in the distribution network. Entire feeder or a portion of it may be fed from another feeder section by closing a tie-switching connecting the feeders and by opening a suitable sectionalizing switch, in order to maintain the radial nature of the feeders. Network reconfiguration in this work pertains to identifying the sectionalizing and tie switches which are to be opened and closed respectively to obtain maximum reduction in power losses. Losses in distribution system, before and after reconfiguration can be found by running load flows. A detailed analysis of network reconfiguration in a RDS can be analyzed by using the flow chart shown in Figure 1.

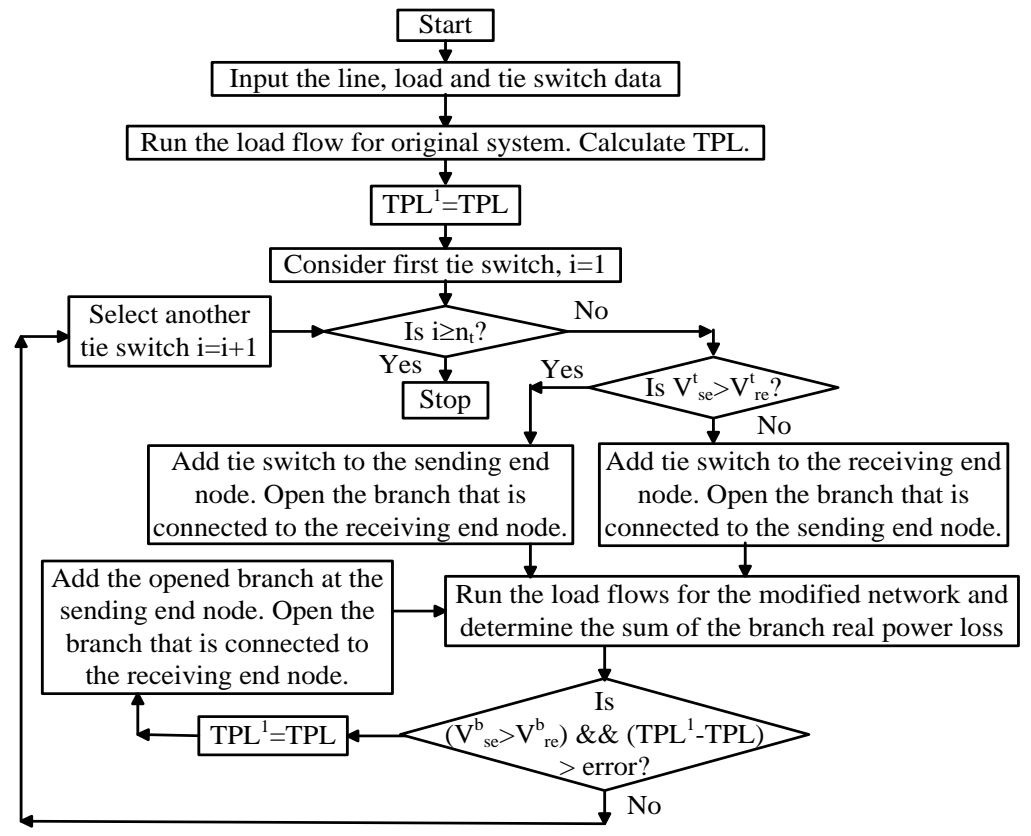

Figure 1. Flowchart for reconfiguration of RDS for loss minimization

In this figure, $\mathrm{n}_{\mathrm{t}}$ is number of tie switches in the RDS. The first step in this method is read the line data and load data and tie switch data of the system. This data includes static data search such as no of sections, no of nodes, no of feeders, section resistances and reactance and dynamic data search such as system configuration, switch table, node voltage and nodal load power components (active and reactive). The 
next step in this method is to run the load flows of base case system. This power loss obtained in a base case system is stored in a temporary variable. The next step is selecting the tie switch of the system [22], [23]. If the selected tie switches till now is equal or greater than the total number of tie switches then the process stops. If the selected tie switches is less than the total number of tie switches then proceed to next step [24]. Then checking the voltages of sending end and receiving end if the sending end voltage is greater than the receiving end voltage, i.e., $\left(V_{s e}^{t}>V_{r e}^{t}\right)$ then add tie switch at the sending end node; open the branch that is connected to receiving end node. Then run the load flows for the modified network and sum the branch real power loss. Then check the voltages of branch that is opened during the network if the $\left(V_{s e}^{t}>V_{r e}^{t}\right)$ and the difference of real power loss of base case system $\left(V_{s e}^{b}>V_{r e}^{b}\right)$ and modified power loss is greater than the error $\left(T P L^{1}-T P L\right)>$ error then the modified real power loss is sent to another variable and further add opened branch at the sending end node that is connected to the receiving end node and run the load flows and do the same analysis [25], [26]. If the condition is not true then select the next tie switch for the process and do the same analysis of the system. This flow chart is useful for any type of network and we can obtain the minimum loss for the system and also we can improve the voltage profile for the entire system.

\section{RESULTS AND DISCUSSION}

In this work 16 bus RDS is used for the analysis and explanation of network reconfiguration. The base MVA and base voltage for 16 bus are considered as 100 MVA and $11 \mathrm{kV}$, respectively. The 16 bus RDS consists of 3 feeders as shown in Figure 2. Branches shown with dashed lines represent tie-switches and that with solid lines represent sectionalizing switches. Normally, the sectionalizing switches are closed and tie switches are open [27]. There are 13 sectionalizing branches and 3 tie-branches with switches in the system considered.

Consider first tie switch which is connected between bus number 5 and bus number 11. Load connected at node 11 in feeder 2 can be shifted to feeder 1 by opening sectionalizing switch 8 and closing tieswitch 14 or load connected at node 5 in feeder 1 can be shifted to feeder 2 by opening sectionalizing switch 2 and closing tie-switch 14 [28]. Either of the above suggested modifications results in system reconfiguration [29]. But, here the aim is to reduce the power losses and to improve the voltage profile. Whichever configuration mentioned above leads to the desired objective is considered as the best configuration. Instead of checking all possible combinations, decision for shifting of load to the other feeder can be taken from the load flow solution for the existing configuration. For base case (initial configuration) shown in Figure 2, the load flow results are as shown in Figure 3.

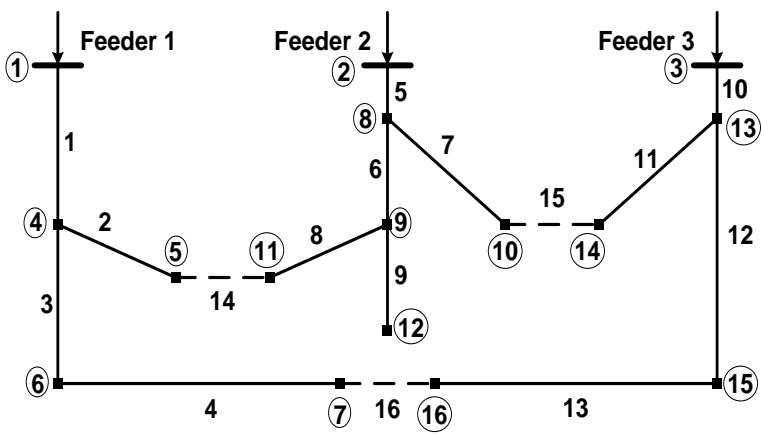

Figure 2. Single line diagram (SLD) of a 16 bus RDS

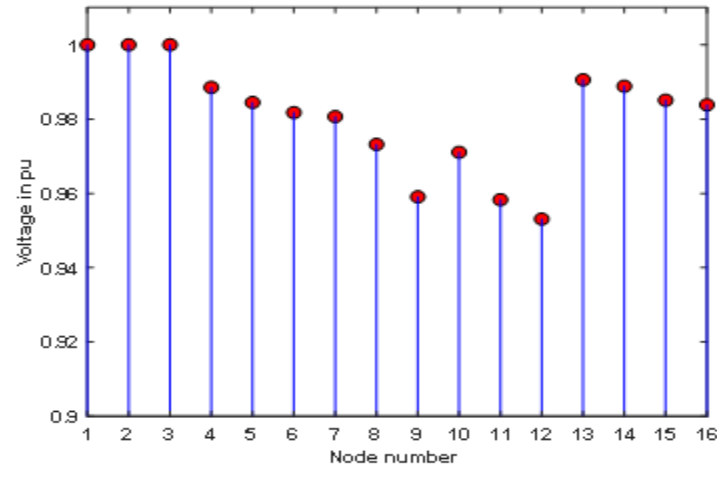

Figure 3. Base case load flow results of 16 bus RDS

Minimum voltage in this case is 0.9531 p.u and it appears at bus number 12 . Total active power loss in the system under base case is $649.58 \mathrm{~kW}$. For the existing configuration for voltages at bus numbers 5 and 11 may be checked to take the decision about switching operation. From Figure 2, it can be seen that voltage at bus 5 is greater than that at bus 11 . Hence, it is appropriate to shift the load connected to bus 11 on to bus 5 by closing the tie switch connected between bus 5 and bus 11 (branch 14) and opening the sectionalizing switch connected between bus 9 and bus 11 .

For the reconfigured system obtained by closing the switch between bus 5 and bus 11 and opening the sectionalizing switch between bus 9 and bus 11 the system appearance is as shown in Figure 4 and the 
obtained load flow results are depicted in Figure 5. Now, the new tie switch is branch number 8 that is connected between bus 9 and bus 11. Minimum voltage in this case is $0.9546 \mathrm{p} . \mathrm{u}$ and it appears at bus number 12. Total active power loss in the system under this case is $626.69 \mathrm{~kW}$. The minimum voltage for this configuration seems to be improved compared to that of base case and also it can be seen that there is a loss reduction of $22.89 \mathrm{~kW}$. Hence this configuration may be treated as the better configuration compared to earlier configuration (base case).

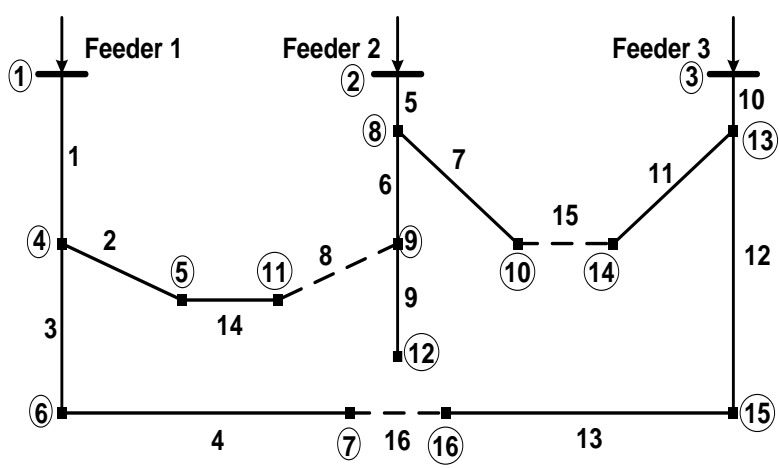

Figure 4. SLD of a 16 bus RDS for the reconfigured system with branch number 8 as tie-switch

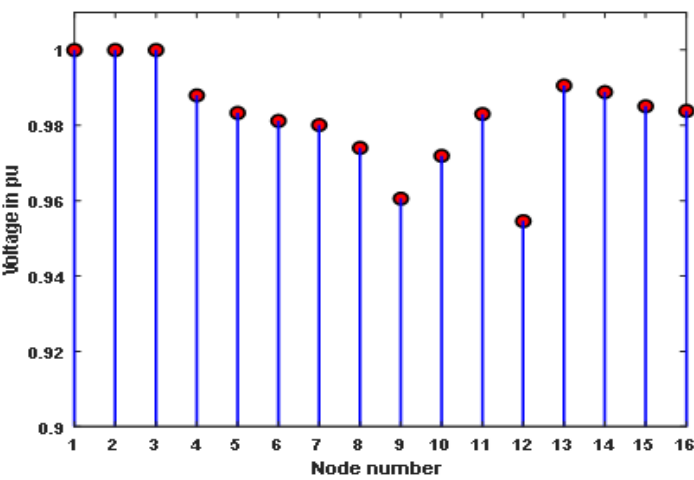

Figure 5. Load flow results of 16 bus RDS due to opening the sectionalizing switch between buses 9 and 11 , and closing the switch between buses 5 and 12

Proceeding further, voltage at bus number 11 is greater than that at bus number 9. So, the next new configuration is obtained by closing the switch between bus numbers 9 and 11, and opening the switch between bus number 9 and bus number 8 so that load at bus number 12 is not isolated. For this new configuration the system appearance is as shown in Figure 6, and the load flow results are as depicted in Figure 7.

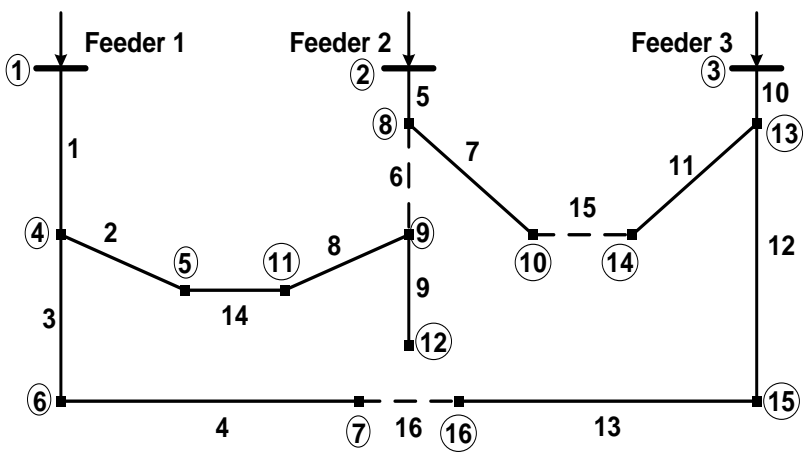

Figure 6. SLD of a 16 bus RDS for the reconfigured system with branch number 6 as tie-switch

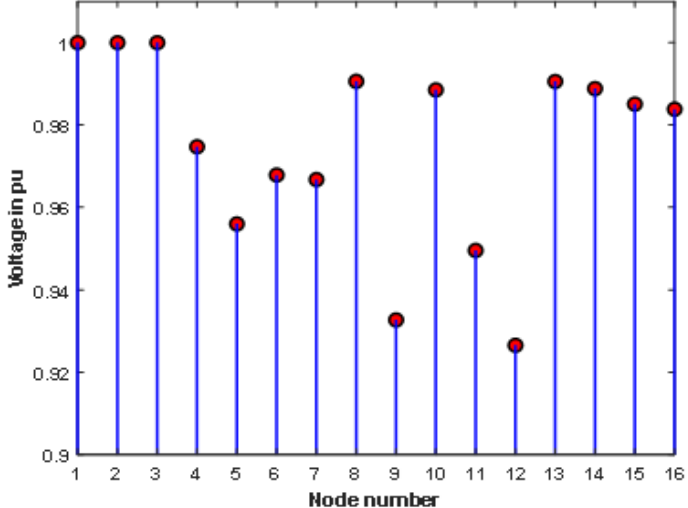

Figure 7. Load flow results of 16 bus RDS due to closing the switch between bus 9 and bus 11 and opening the sectionalizing switch between bus 8 and bus 9

Minimum voltage for this configuration is seen to be 0.9265 p.u and it appears at bus number 12 . Since minimum voltage is less than 0.95 p.u this configuration is not useful. Hence, we cannot consider this configuration for the selected tie-switch or proceed further and so, the previous configuration is held to be the best configuration for the tie-switch connecting feeders 1 and 2 .

Now consider the second tie-switch which is connected between bus number 10 and bus number 14 . Load flow results for the previous selected configuration are shown in Figure 5. From this figure it can be 
said that voltage at bus number 14 is greater than voltage at bus number 10 . Hence load on bus number 10 may be transferred to bus number 14 by closing the tie switch number 15 and opening the sectionalizing switch number 7. The resulting system is depicted in Figure 8 and the load flow results are shown in Figure 9.

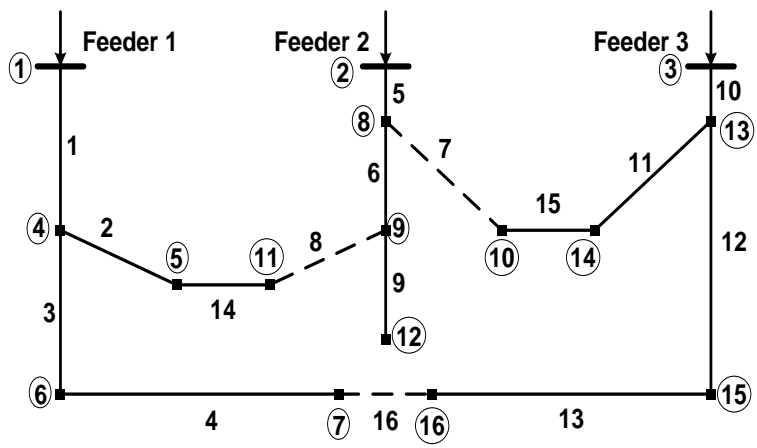

Figure 8. SLD of a 16 bus RDS for the reconfigured system with branch number 7 as tie-switch

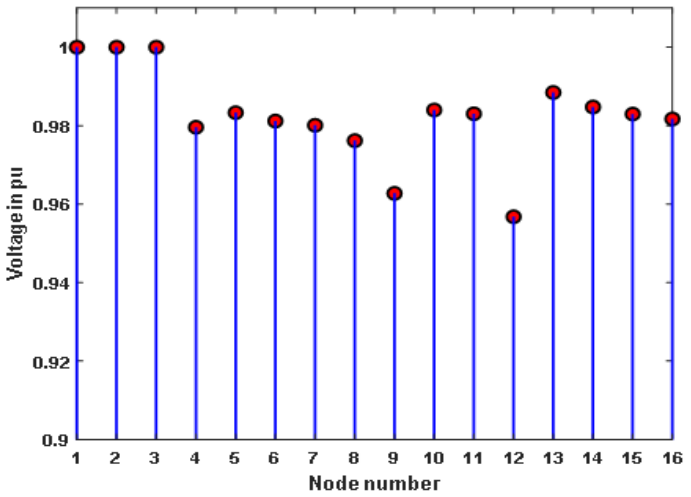

Figure 9. Load flow results of 16 bus RDS due to closing the switch between bus 10 and bus 14 and opening the sectionalizing switch between bus 8 and bus 10

Now, the new tie switch is branch number 7 that is connected between bus 8 and bus 10 . Minimum voltage in this case is $0.9568 \mathrm{p} . \mathrm{u}$ and it appears at bus number 12. Total active power loss in the system under this case is $599.56 \mathrm{~kW}$. The minimum voltage for this configuration seems to be improved compared to that of previous configuration and also it can be seen that there is a loss reduction of $50.02 \mathrm{~kW}$. Hence this configuration may be treated as the better configuration compared to earlier configuration.

Proceeding further, voltage at bus number 10 is greater than that at bus number 8 . So, the next new configuration is obtained by closing the switch between bus number 8 and bus number 10, and opening the switch between bus number 2 and bus number 8 so that no closed loop is formed between feeder 2 and feeder 3. For this new configuration the system appearance is as shown in Figure 10 and the load flow results are as depicted in Figure 11. Minimum voltage for this configuration is seen to be 0.8766 p.u and it appears at bus number 12. Since minimum voltage is less than 0.95 p.u this configuration is not useful. Hence, we cannot consider this configuration for the selected tie-switch or proceed further and so, the previous configuration is held to be the best configuration for the tie-switch connecting feeders 2 and 3 .

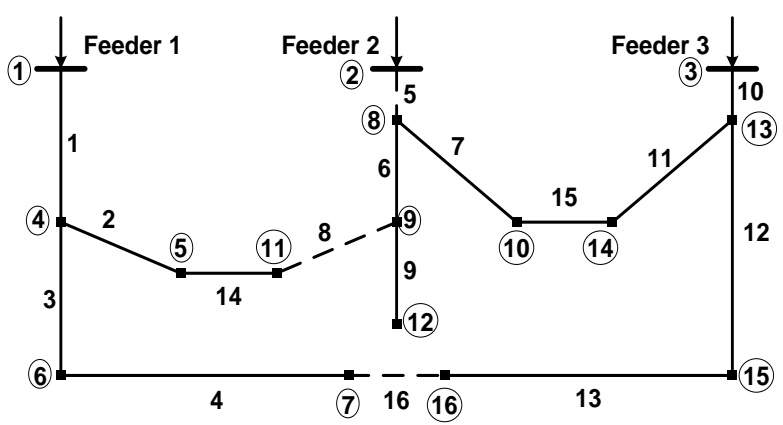

Figure 10. SLD of a 16 bus RDS for the reconfigured system with branch number 5 as tie-switch

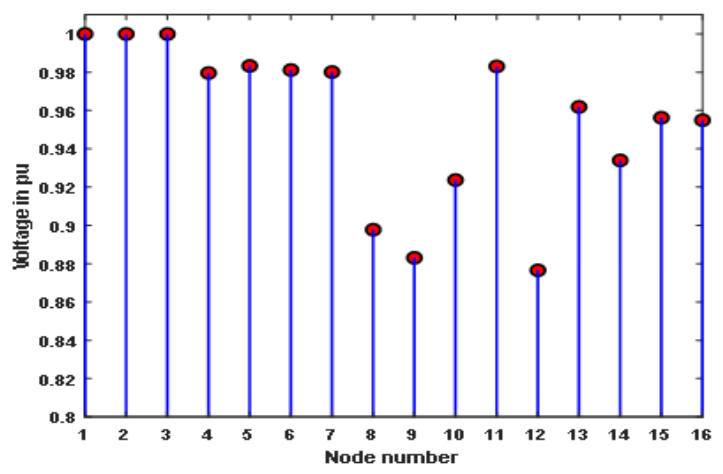

Figure 11. Load flow results of 16 bus RDS due to closing the switch between bus 8 and bus 10 and opening the sectionalizing switch between bus 2 and bus 8 
Now consider the third tie-switch which is connected between bus number 7 and bus number 16 . Load flow results for the previous selected configuration are shown in Figure 9. From this figure it can be said that voltage at bus number 16 is greater than voltage at bus number 7 . Hence load on bus number 7 may be transferred to bus number 16 by closing the tie switch number 16 and opening the sectionalizing switch number 4 . The resulting system is shown in Figure 12 and the load flow results are shown in Figure 13.

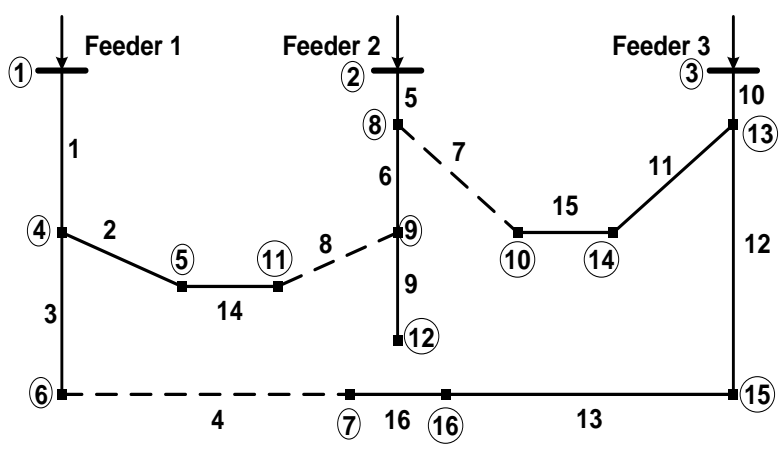

Figure 12. SLD of a 16 bus RDS for the reconfigured system with branch number 4 as tie-switch

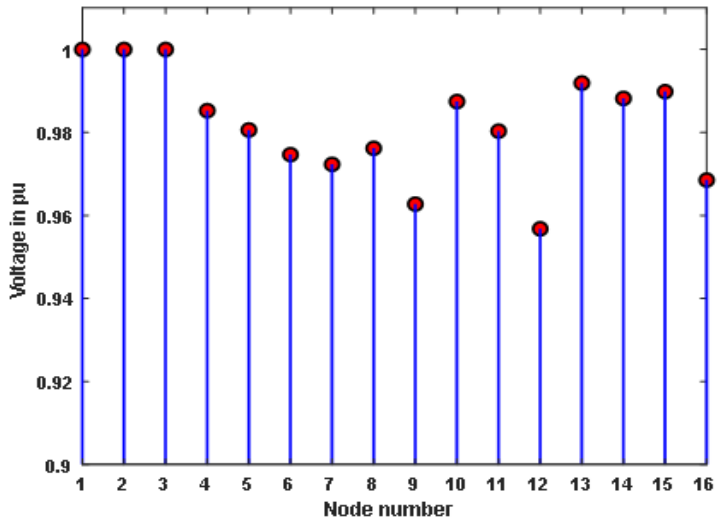

Figure 13. Load flow results of 16 bus RDS due to closing the switch between bus 7 and bus 16 and opening the sectionalizing switch between bus 6 and bus 7

Now, the new tie switch is branch number 4 that is connected between bus number 6 and bus number 7. Minimum voltage in this case is $0.9568 \mathrm{p} . \mathrm{u}$ and it appears at bus number 12 . Total active power loss in the system under this case is $630.23 \mathrm{~kW}$. The minimum voltage for this configuration seems to be same as that of previous configuration but it can be seen that there is an increase in loss of $30.67 \mathrm{~kW}$. Hence, we cannot consider this configuration for the selected tie-switch or proceed further and, the previous configuration is held to be the best configuration for the tie-switch connecting feeders 1 and 3 . So, the configuration shown in Figure 8 is the final best configuration which minimizes the losses in the given distribution system. Comparison of node voltages before and after the reconfiguration is shown in Figure 14. Comparison of various other parameters before and after reconfiguration is shown in Table 1.

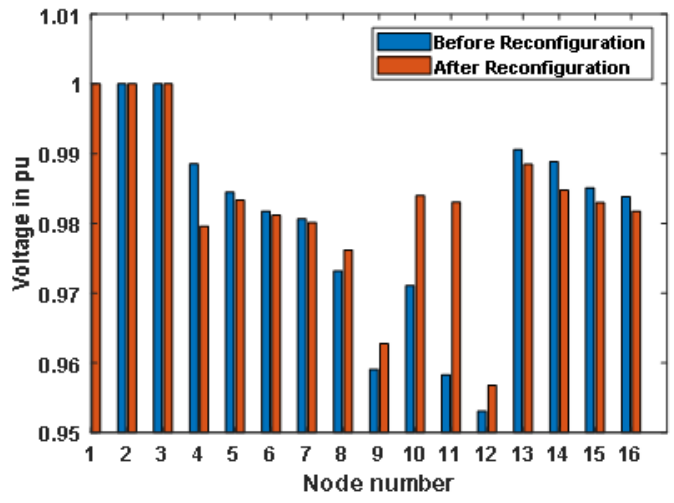

Figure 14. Comparison of node voltages before and after reconfiguration for a 16 bus RDS

Table 1. Simulation results for 16 bus RDS before and after network reconfiguration

\begin{tabular}{ccc}
\hline & Before network reconfiguration & After network reconfiguration \\
\hline Tie switches & $14,15,16$ & $7,8,16$ \\
Power loss & $649.58 \mathrm{~kW}$ & $599.56 \mathrm{~kW}$ \\
Power loss reduction & - & $7.7 \%$ \\
Minimum voltage & $0.9531 \mathrm{pu}$ & 0.9568 \\
\hline
\end{tabular}


From Figure 14, it can be seen that the voltages at node numbers 10 and 11 have drastically improved and at node 12 the voltage is improved to a reasonable extent. Though, there is a decrease in voltages at some nodes, it is to a reasonable extent. From Table 1, it can be seen that there is a reduction in power loss of $7.7 \%$.

\section{CONCLUSION}

This paper has presented a distribution network reconfiguration approach to determine the optimum case switch that will provide minimal losses so that all system restrictions including node voltages, radial network should be met. Minimizing distribution system losses with network reconfiguration is a difficult problem that several researches have studied. Because a problem of non-linear optimization is the distribution system reconfiguration for loss minimization, it poses an immense code burden for even moderate sized systems. The proposed approach is applied to test network of 16 nodes with three radial feeders and a distribution network of 33 nodes.

\section{ACKNOWLEDGEMENTS}

This research work was funded by "Woosong University's Academic Research Funding-2021". We thank "Woosong University Educational Foundation", Daejeon, Republic of Korea for providing the necessary facilities for doing this research work.

\section{REFERENCES}

[1] S. Sivanagaraju and T. Ramana, "A Simple Method for Feeder Reconfiguration and Service Restoration of Distribution Networks," Electric Power Components and Systems, vol. 32, no. 9, pp. 883-892, 2004, doi: 10.1080/15325000490253579.

[2] A. O. Salau, Y. W. Gebru, and D. Bitew, "Optimal network reconfiguration for power loss minimization and voltage profile enhancement in distribution systems", Heliyon, vol. 6, no. 6, Jun. 2020, doi: 10.1016/j.heliyon.2020.e04233.

[3] A. J. Nowdeh, et al., "Meta-heuristic matrix moth-flame algorithm for optimal reconfiguration of distribution networks and placement of solar and wind renewable sources considering reliability," Environmental Technology \& Innovation, vol. 20, Nov. 2020, doi: 10.1016/j.eti.2020.101118.

[4] Q. Shi, et al., "Network reconfiguration and distributed energy resource scheduling for improved distribution system resilience," International Journal of Electrical Power \& Energy Systems, vol. 124, p. 106355, Jan. 2021, doi: 10.1016/j.ijepes.2020.106355.

[5] S. Essallah and A. Khedher, "Optimization of distribution system operation by network reconfiguration and DG integration using MPSO algorithm," Renewable Energy Focus, vol. 34, pp. 37-46, Sept. 2020, doi: 10.1016/j.ref.2020.04.002.

[6] R. Pegado, Z. Naupari, Y. Molina, and C. Castillo, "Radial distribution network reconfiguration for power losses reduction based on improved selective BPSO," Electric Power Systems Research, vol. 169, pp. 206-213, Apr. 2019, doi: 10.1016/j.ref.2020.04.002.

[7] A. A. M. Raposo, A. B. Rodrigues, M. G. da Silva, "Robust meter placement for state estimation considering Distribution Network Reconfiguration for annual energy loss reduction," Electric Power Systems Research, vol. 182, p. 106233, May 2020, doi: 10.1016/j.epsr.2020.106233.

[8] M. I. Pathan, M. A. Muhaini, and S. Z. Djokic, "Optimal reconfiguration and supply restoration of distribution networks with hybrid microgrids," Electric Power Systems Research, vol. 187, p. 106458, Oct. 2020, doi: 10.1016/j.epsr.2020.106458.

[9] J. Shukla, B. K. Panigrahi, and P. K. Ray, "Stochastic reconfiguration of distribution system considering stability, correlated loads and renewable energy based DGs with varying penetration," Sustainable Energy, Grids and Networks, vol. 23, p. 100366, Sept. 2020, doi: 10.1016/j.segan.2020.100366.

[10] L. W.de Oliveira, S. CarneiroJr., E. J.de Oliveira, J. L. R. Pereira, I. C. Silva Jr., and J. S. Costa, "Optimal reconfiguration and capacitor allocation in radial distribution systems for energy losses minimization," International Journal of Electrical Power \& Energy Systems, vol. 32, no. 8, pp. 840-848, Oct. 2010, doi: 10.1016/j.ijepes.2010.01.030

[11] L. W. de Oliveira, E. J. de Oliveira, F. V. Gomes, I. C. Silva Jr., A. L. M. Marcato, and P. V. C. Resende, "Artificial Immune Systems applied to the reconfiguration of electrical power distribution networks for energy loss minimization," International Journal of Electrical Power \& Energy Systems, vol. 56, pp. 64-74, Mar. 2014, doi: 10.1016/j.ijepes.2013.11.008.

[12] Y. Merzoug, B. Abdelkrim, and B. Larbi, "Distribution network reconfiguration for loss reductionusing PSO method," International Journal of Electrical and Computer Engineering, vol. 10, no. 5, pp. 5009-5015, Oct. 2020, doi: 10.11591/ijece.v10i5.pp5009-5015. 
[13] A. P. Hota and S. Mishra, "Loss allocation in distribution networks with distributed generators undergoing network reconfiguration," International Journal of Electrical and Computer Engineering, vol.10, no.4, pp. 3375-3383, Aug. 2020, doi: 10.11591/ijece.v10i4.pp3375-3383.

[14] M. Q. Duran, J. E. Candelo, and J. S. Ortiz, "A modified backward/forward sweep-based method for reconfiguration of unbalanced distribution networks," International Journal of Electrical and Computer Engineering, vol. 9, no. 1, pp. 85-101, Feb. 2019, doi: 10.11591/ijece.v9i1.pp85-101.

[15] O. M. Neda, "A new hybrid algorithm for solving distribution network reconfiguration under different load conditions," Indonesian Journal of Electrical Engineering and Computer Science, vol. 20, no. 3, pp. 1118-1127, Dec. 2020, doi: 10.11591/ijeecs.v20.i3.pp1118-1127.

[16] R. D. Mohammedi, R. Zine, M. Mosbah, and S. Arif, "Optimum Network Reconfiguration using Grey Wolf Optimizer," TELKOMNIKA, pp. 2428-2435, vol. 16, no. 5, Oct. 2018, doi: 10.12928/telkomnika.v16i5.10271.

[17] A. V. S. Reddy, M. D. Reddy, and M. S. K. Reddy, "Network Reconfiguration of Distribution System for Loss Reduction Using GWO Algorithm," International Journal of Electrical and Computer Engineering, vol. 7, no. 6, pp. 3226-3234, Dec. 2017, doi: ijece.v7i6.pp3226-3234.

[18] T. T. Nguyen, "Electric distribution network reconfiguration for power loss reduction based on runner root algoritm," International Journal of Electrical and Computer Engineering, vol. 10, no. 5, pp. 5016-5024, Oct. 2020, doi: 10.11591/ijece.v10i5.pp5016-5024.

[19] J. Zhang, X. Yuan and Y. Yuan, "A novel genetic algorithm based on all spanning trees of undirected graph for distribution network reconfiguration," Journal of Modern Power Systems and Clean Energy, vol. 2, no. 2, pp. 143149, Jun. 2014, doi: 10.1007/s40565-014-0056-0.

[20] C. Lee, C. Liu, S. Mehrotra and Z. Bie, "Robust Distribution Network Reconfiguration," in IEEE Transactions on Smart Grid, vol. 6, no. 2, pp. 836-842, March 2015, doi: 10.1109/TSG.2014.2375160.

[21] Z. Yin, X. Ji, Y. Zhang, Q. Liu, and X. Bai, "Data-driven approach for real-time distribution network reconfiguration," IET Generation, Transmission \& Distribution, vol. 14, no. 13, pp. 2450-2463, 2020, doi: 10.1049/iet-gtd.2019.1733.

[22] H. Souifi, O. Kahouli, and H. H. Abdallah, "Multi-objective distribution network reconfiguration optimization problem," Electrical Engineering, vol. 101, pp. 45-55, 2019, doi: 10.1007/s00202-019-00755-3.

[23] B. Vasudevan and A.K. Sinha, "Reliability improvement of reconfigurable distribution system using GA and PSO," Electrical Engineering, vol. 100, pp. 1263-1275, 2018, doi: 10.1007/s00202-017-0580-9.

[24] Roosta, H. R. Eskandari, and M. H. Khooban, "Optimization of radial unbalanced distribution networks in the presence of distribution generation units by network reconfiguration using harmony search algorithm," Neural Computing and Applications, vol. 31, pp. 7095-7109, 2019, doi: 10.1007/s00521-018-3507-0.

[25] T. T. Nguyen, T. T. Nguyen, L. T. Duong, and V. A. Truong, "An effective method to solve the problem of electric distribution network reconfiguration considering distributed generations for energy loss reduction," Neural Computing and Applications, vol. 33, pp. 1625-1641, 2020, doi: 10.1007/s00521-020-05092-2.

[26] A. Fathy, M. El-Arini, and O. El-Baksawy, "An efficient methodology for optimal reconfiguration of electric distribution network considering reliability indices via binary particle swarm gravity search algorithm," Neural Computing and Applications, vol. 30, pp. 2843-2858, 2018, doi: 10.1007/s00521-017-2877-z.

[27] S. Sivanagaraju, B. E. Jagadeesh, Y. Srikanth, and B. N. Rao, "A new method for network reconfiguration of radial distribution systems for loss minimization," Water and Energy International, vol. 62, no. 03, pp. 56-62, 2005.

[28] R. A. Jabr, I. Džafić and I. Huseinagić, "Real Time Optimal Reconfiguration of Multiphase Active Distribution Networks," in IEEE Transactions on Smart Grid, vol. 9, no. 6, pp. 6829-6839, Nov. 2018, doi: 10.1109/TSG.2017.2724766.

[29] N. R. Battu, A. R. Abhyankar and N. Senroy, "Distribution system reconfiguration in a deregulated environment," 2016 IEEE 6th International Conference on Power Systems (ICPS), 2016, pp. 1-6, doi: 10.1109/ICPES.2016.7584214. 